\title{
Effect of L-carnitine on exercise performance in patients with mitochondrial myopathy
}

\author{
A.C. Gimenes ${ }^{1}$, D.M. Bravo ${ }^{1}$, L.M. Nápolis ${ }^{1}$, M.T. Mello ${ }^{2}$, A.S.B. Oliveira ${ }^{3}$, J.A. Neder ${ }^{1}$ and L.E. Nery ${ }^{1}$ \\ ${ }^{1}$ Setor de Função Pulmonar e Fisiologia Clínica do Exercício, Universidade Federal de São Paulo, São Paulo, SP, Brasil \\ ${ }^{2}$ Departamento de Psicobiologia, Universidade Federal de São Paulo, São Paulo, SP, Brasil \\ ${ }^{3}$ Setor de Doenças Neuromusculares, Universidade Federal de São Paulo, São Paulo, SP, Brasil
}

\begin{abstract}
Exercise intolerance due to impaired oxidative metabolism is a prominent symptom in patients with mitochondrial myopathy (MM), but it is still uncertain whether L-carnitine supplementation is beneficial for patients with MM. The aim of our study was to investigate the effects of L-carnitine on exercise performance in MM. Twelve MM subjects (mean age $\pm S D=35.4 \pm 10.8$ years) with chronic progressive external ophthalmoplegia (CPEO) were first compared to 10 healthy controls (mean age $\pm S D=29 \pm 7.8$ years) before they were randomly assigned to receive L-carnitine supplementation ( $3 \mathrm{~g} /$ daily) or placebo in a double-blind crossover design. Clinical status, body composition, respiratory function tests, peripheral muscle strength (isokinetic and isometric torque) and cardiopulmonary exercise tests (incremental to peak exercise and at $70 \%$ of maximal), constant work rate (CWR) exercise test, to the limit of tolerance [Tlim]) were assessed after 2 months of L-carnitine/placebo administration. Patients with MM presented with lower mean height, total body weight, fat-free mass, and peripheral muscle strength compared to controls in the pre-test evaluation. After L-carnitine supplementation, the patients with MM significantly improved their Tlim ( $14 \pm 1.9$ vs $11 \pm 1.4 \mathrm{~min})$ and oxygen consumption $\left(\dot{\mathrm{V}}_{2}\right)$ at CWR exercise, both at isotime (1151 \pm 115 vs $1049 \pm 104 \mathrm{~mL} / \mathrm{min})$ and at Tlim $(1223 \pm 114$ vs $1060 \pm 108 \mathrm{~mL} / \mathrm{min})$. These results indicate that L-carnitine supplementation may improve aerobic capacity and exercise tolerance during high-intensity CWRs in MM patients with CPEO.
\end{abstract}

Key words: Exercise tolerance; Muscle strength; Mitochondrial myopathy; L-carnitine supplementation

\section{Introduction}

Mitochondrial diseases caused by mutations in nuclear and mitochondrial DNA (mtDNA) are recognized as the most common types of inherited neuromuscular diseases. These genetic defects in oxidative phosphorylation lead to specific abnormalities in exercise performance, such as a reduced maximal whole-body oxygen consumption and elevated lactate levels during exercise $(1,2)$.

Exercise intolerance, particularly in the form of chronic progressive external ophthalmoplegia (CPEO), is a very common symptom in individuals with mitochondrial myopathy (MM) and is typically associated with undue fatigue at relatively low exertion levels (3). The most prominent symptoms come from skeletal muscle, due to their lower oxidative capacity and significant levels of mutant mtDNA compared with other tissues. Impaired oxidative phosphorylation may result in exercise intolerance breathlessness, exaggerated lactic acidosis, and low exercise capacity (4). This effect may augment the patient's functional limitations and lead to a vicious cycle of exercise intolerance exacerbation (4).

Although there is no specific therapy for MM $(5,6)$, Lcarnitine, an amine administered as a dietary supplement, has been reported to increase the influx of fatty acids into the mitochondria, facilitating pyruvate oxidation and reducing lactate synthesis (7). There is currently no available disease-modifying therapy for MM. Several agents, mostly nutritional supplements, including Lcarnitine, have been investigated with double-blind, placebo-controlled studies, but none has demonstrated effects in clinical disease end-points, although numerous non-blind studies and case reports have suggested that it is beneficial (8).

Thus, the purpose of the present study was to determine whether L-carnitine can improve exercise tolerance in MM subjects. The central hypothesis was that the supplement would induce physiological changes by increasing oxidative metabolism, resulting in beneficial

Correspondence: A.C. Gimenes: <anacgimenes@uol.com.br>; L.E. Nery: <lenery@pneumo.epm>. 
effects on skeletal muscle performance and exercise tolerance in these patients.

\section{Material and Methods}

Twelve patients with biopsy-proven MM followed at the Neuromuscular Division of the Escola Paulista de Medicina at the Universidade Federal de São Paulo (Unifesp) agreed to participate in the study. Patients were diagnosed after clinical and biopsy evaluation. The muscle biopsy was obtained from the right vastus lateralis at least 3 months before the beginning of the study protocol. Samples were frozen in isopentane cooled by liquid nitrogen for histological and histocytochemical analysis. All muscle biopsies exhibited abnormal mitochondrial proliferation as ragged red fibers under modified Gomori trichrome stain and succinate dehydrogenase staining, and as cytochrome c oxidase-deficient or negative fibers, as well as mosaic patterns dominated by type 1 fibers $(8,9)$.

The inclusion criteria for the trial were: i) MM with CPEO; ii) age $>14$ years; and iii) complaint of exercise intolerance, mild fixed limb weakness, or myalgias. The exclusion criteria were: i) cardiac pacemaker; ii) severe limb weakness; iii) concomitant ergogenic supplementation treatment; iv) renal, cardiac, or pulmonary dysfunction; or v) participation in regular physical activity in the preceding year.

Written informed consent was obtained from all patients, and the study protocol was approved by the Ethics Committee of the Universidade Federal de São Paulo (\#0943/03).

Ten age- and gender-matched healthy volunteers constituted the control group. To match the habitual physical activities of the patients, controls were required to have very low daily physical activity scores as determined by the Baecke questionnaire (a total score of $<6$ ) (10).

\section{Study protocol}

The study protocol for MM patients followed a doubleblind placebo/L-carnitine controlled crossover design. Before entering the study, all patients were evaluated for compliance of the proposed tests (pre-test evaluation). Control subjects did not receive any supplementary intervention and were only evaluated at the beginning of the study with the same tests, excluding the constant work rate (CWR) exercise test (Figure 1). For the double-blind trial, enrolled patients were randomly assigned to receive either $3 \mathrm{~g} \mathrm{~L}$-carnitine or $3 \mathrm{~g}$ placebo in one daily dose (with breakfast or lunch) for 8 weeks. They took identical-looking capsules (DrogaDerma, Brazil). The second evaluation was performed 8 weeks after the patients had received either L-carnitine or placebo. After that, a 4-week washout period was carried out to minimize the drug effect and the third evaluation was performed after L-carnitine/placebo crossover (Figure 1). Most studies that administered Lcarnitine to patients with chronic diseases utilized daily doses between 2 and $4 \mathrm{~g}(11,12)$. The $3-\mathrm{g}$ dose given in this study has been used empirically in the Neuromuscular Division of the Escola Paulista de Medicina, Unifesp.

Treatment adherence was confirmed by the patient during weekly phone calls and monthly appointments at the outpatient respiratory clinic. In these consultations, patients were asked to bring their empty bottles of Lcarnitine and receive a new monthly supplement supply. They also reported possible side effects attributed to the supplement or placebo. The patients had $100 \%$ compliance with the protocol, and no patient dropped out during the study.

\section{Measurements}

Body composition. The patient's mid-arm circumference was measured, and the skin fold thicknesses at the bicipital and tricipital levels were obtained using a skin-fold caliper. The arm muscle circumference $(\mathrm{cm})$ was derived from these readings. Bioelectrical impedance (Quantum BIA-101Q, RJL-101 ${ }^{\mathrm{TM}}$, USA) was used to estimate the total body fat-free mass (FFM, kg). The FFM index (FFMI) was calculated as the ratio of the patient's FFM to his or her height $\left(\mathrm{m}^{2}\right)$.

Pulmonary function testing. Spirometry lung volumes and maximal voluntary ventilation (MVV) were obtained in all subjects (Elite series, Medical Graphics Co. [MGC], USA). Data are reported as a percentage of the predicted values obtained in healthy Brazilian subjects (13-15).

Cardiopulmonary exercise testing (CPET). Incremental cardiopulmonary exercise tests (ICPET) were performed using an electromagnetically braked cycle ergometer (CPE 2000, MGC). The gas exchange, ventilator and cardiovascular variables were analyzed breath-by-breath $\left(\mathrm{CardiO}_{2}\right.$ System, MGC) during an ICPET following a linear "ramp" pattern of increase (16): $5-15 \mathrm{~W} / \mathrm{min}$ and $15-25 \mathrm{~W} / \mathrm{min}$ in patients and healthy subjects, respectively. This protocol was designed such that the test time was more than $8 \mathrm{~min}$ and less than $12 \mathrm{~min}$, based on "symptom-limited interruption" for all the participants. The following variables were reported as 15-s means: oxygen uptake $\left(\dot{\mathrm{V}} \mathrm{O}_{2}\right.$ in $\left.\mathrm{mL} / \mathrm{min}\right)$, carbon dioxide output $\left(\dot{\mathrm{V}} \mathrm{CO}_{2}\right.$ in $\mathrm{mL} /$ min), minute ventilation ( $\dot{\mathrm{V}}_{\mathrm{E}}$ in $\mathrm{L} / \mathrm{min}$ ), and the end-tidal partial pressures of oxygen and carbon dioxide $\left(\mathrm{PETO}_{2}\right.$ and $\left.\mathrm{PETCO}_{2}, \mathrm{mmHg}\right)$. Subject heart rate $(\mathrm{HR}$, bpm) was automatically calculated from the R-R distance obtained with 12-lead electrocardiogram tracing $\left(\mathrm{CardiO}_{2}\right.$ System, MGC). The $\dot{\mathrm{V}} \mathrm{O}_{2}$ at the estimated lactate threshold was evaluated using the gas-exchange threshold (GET) (17). The average $\dot{\mathrm{VO}}_{2}$ in the last $15 \mathrm{~s}$ of exercise was considered representative of the subject's peak $\dot{\mathrm{V}} \mathrm{O}_{2}$ (18). On a different day, patients also underwent a CWR exercise test on a cycle ergometer with a load corresponding to $70 \%$ of that obtained in the peak 

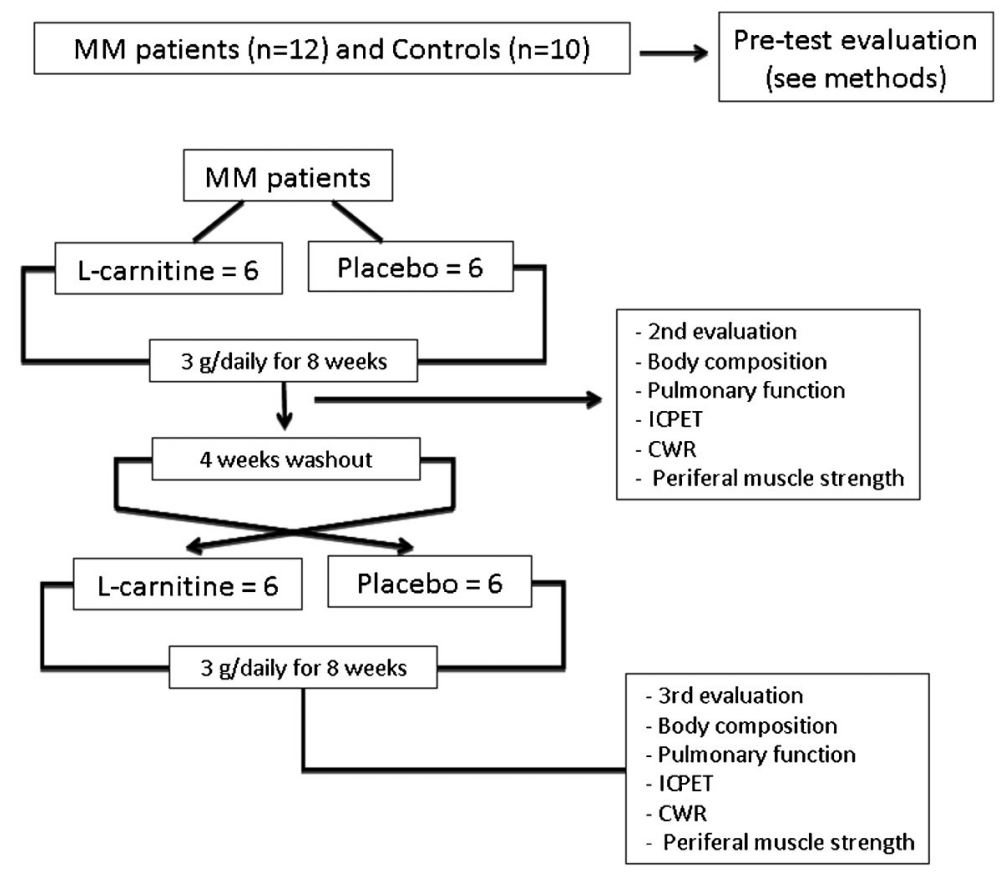

Figure 1. Design of study protocol. MM: mitochondrial myopathy; ICPET: incremental cardiopulmonary exercise test; CWR: constant work rate. exercise to their limit of tolerance (Tlim).

Blood lactate. Blood samples from the earlobe were collected at peak of the ICPET and in the 5 th min of the recovery period after L-carnitine or placebo treatment. These samples were analyzed on a lactimeter YSI model 1500 Sport (Yellow Springs Inc., USA) using an electroenzymatic method.

Peripheral muscle testing. The isokinetic muscle endurance of the dominant knee extensor (quadriceps) was measured using a computer-based dynamometer (Contrex CE, Switzerland). The subject was seated upright on the dynamometer chair, with his or her back fully supported. The lever arm's mechanical axis of rotation was aligned with the knee's axis of rotation. Muscle strength (a concentric evaluation of the knee's flexion and extension movements) was determined from the peak torque (PT) measured during five consecutive maximal repetitions at an angular velocity at $60 \%$ s. Isometric torque (IT) was evaluated from the maximal knee strength sustained for $5 \mathrm{~s}$ at $60^{\circ}$. The endurance of the quadriceps was determined as the total work (TW) achieved during 20 consecutive maximal repetitions at an angular velocity of $300^{\circ} / \mathrm{s}$ (19).

\section{Statistical analysis}

Statistical analysis was performed using SPSS 15.0 for Windows (USA). To compare data from controls with the placebo data of patients, we utilized $t$-tests for independent samples, and the results are reported as means and standard deviations. For comparison of the effect of placebo and L-carnitine in the patient group, a crossover trial was performed using a generalized linear mixed model (GLM) design based on repeated measures to account for treatment and carry-over effects (placebo $\rightarrow$ L-carnitine vs L-carnitine $\rightarrow$ placebo) (Figure 1). For this analysis, we performed Mauchly's test of sphericity, and when this was not met, we applied the Huynh correction (20). In case of no influence of the intervention sequence, the randomized patients were analyzed as a single group $(n=12)$.

\section{Results}

During pre-test assessment, patients with MM were found to have lower weight, height, body mass index and FFMI, compared to normal subjects ( $P<0.05$, Table 1$)$. The residual volume (RV; \% predicted) was significantly increased, and the MVV (\% predicted) was significantly lower in patients compared to controls. Patients also presented significantly lower peak torque, isometric torque, and total work (Table 2).

We also observed that peak $\mathrm{VO}_{2}$ (in $\mathrm{mL} / \mathrm{min}$ and as a $\%$ predicted), peak work rate, and GET were significantly lower in patients compared to controls (Table 3). At peak exercise, patients with MM predominantly reported leg fatigue as evaluated by the Borg scale for lower limbs (Table 3).

No anthropometric or peripheral muscle test differences were observed after L-carnitine supplementation, compared to patients who received placebo (Table 4). Furthermore, MM subjects maintained the same body mass index, FFM, FFMI, and arm muscle circumference. 
However, we did find a significant improvement in inspiratory capacity, both in absolute and \% predicted, after L-carnitine supplementation.

With regard to the ICPET, no significant differences of metabolic, ventilator, or cardiovascular variables were detected comparing the studied interventions in the patient group (Table 5). In contrast, during CWR symptom-limited exercise testing (Table 6), we observed a significantly longer Tlim, higher $\dot{\mathrm{VO}}_{2}$ at the 6th min of exercise (isotime) and at Tlim after L-carnitine supplementation compared to the placebo. We also observed a significantly higher oxygen pulse $\left(\dot{\mathrm{V}}_{2} / \mathrm{HR}, \mathrm{mL} /\right.$ beat $)$ value at Tlim after L-carnitine compared to placebo. Importantly, at isotime, the gas-exchange ratio was lower after L-carnitine compared to placebo.

\section{Discussion}

In the evaluation of the physiological responses after a double-blind placebo/L-carnitine crossover design in patients with MM, we observed that L-carnitine ( $3 \mathrm{~g} /$ day) improved aerobic capacity and exercise tolerance during a high-intensity constant-work exercise in a select group of MM patients with CPEO.

\section{Clinical characteristics and resting pulmonary function of patients with MM}

As previously reported (21), our patients had lower weight, height, and muscle mass compared to controls and a significantly higher mean RV, RV to total lung capacity ratio, and reduced MVV compared to controls.
These findings might be related to a restrictive ventilatory pattern that is commonly observed in patients with neuromuscular diseases (22).

In the peripheral muscle evaluation, our patients exhibited significantly less muscle strength than controls, suggesting that the reduction in peripheral muscle strength might be related to alterations in oxidative phosphorylation, which is the hallmark characteristic of these patients $(4,21,22)$. Our patients also showed significantly lower maximum exercise capacity and peak $\dot{\mathrm{VO}}_{2}$ compared to controls. Several studies evaluating exercise tolerance in $\mathrm{MM}$ have demonstrated markedly low $\dot{\mathrm{V}}_{2}$ peak (23-27), reflecting impaired muscle mitochondrial oxidative phosphorylation. The maximal exercise capacity of MM subjects has been shown to directly correlate with the degree of $\mathrm{O}_{2}$ extraction in the impaired muscle, which enables the use of the systemic arterial to venous $\mathrm{O}_{2}$ difference as a surrogate marker for mitochondrial oxidative capacity $(3,4)$.

\section{Effect of L-carnitine supplementation on exercise performance in patients with MM}

After oral supplementation of $3 \mathrm{~g}$ of L-carnitine over a 2-month period, we observed a statistically significant change in the patients' body composition as evaluated by their body mass index, FFM, and FFMI. To our knowledge, no studies have correlated changes in body composition with L-carnitine supplementation in patients with MM. Chazot et al. administered L-carnitine to chronic renal failure patients on dialysis and also found no changes in the body composition after this period of

Table 1. Characteristics of patients with mitochondrial myopathy (MM) and healthy controls.

\begin{tabular}{lcc}
\hline & MM $(\mathrm{n}=12)$ & Controls $(\mathrm{n}=10)$ \\
\hline Age $($ years $)$ & $34.5 \pm 11.2$ & $29 \pm 7.8$ \\
Gender $(\mathrm{M} / \mathrm{F})$ & $8 / 4$ & $6 / 4$ \\
Weight $(\mathrm{kg})$ & $53.1 \pm 13.5^{*}$ & $71.4 \pm 9.8$ \\
Height $(\mathrm{m})$ & $1.61 \pm 0.83^{*}$ & $1.70 \pm 0.64$ \\
FFM $(\mathrm{kg})$ & $42.0 \pm 9.3^{*}$ & $52.5 \pm 7.9$ \\
BMI $\left(\mathrm{kg} / \mathrm{m}^{2}\right)$ & $20.6 \pm 4.3^{*}$ & $24.5 \pm 2.8$ \\
AMC $(\mathrm{cm})$ & $19.4 \pm 4.4^{*}$ & $24.8 \pm 4.7$ \\
FFMI $\left(\mathrm{kg} / \mathrm{m}^{2}\right)$ & $15.6 \pm 2.4^{*}$ & $18 \pm 2.0$ \\
FVC $(\%$ pred $)$ & $89 \pm 13^{*}$ & $96.2 \pm 9.8$ \\
FEV $(\%$ pred $)$ & $87 \pm 16$ & $93 \pm 10$ \\
FEV 1 FVC $(\%)$ & $80 \pm 0.1$ & $80 \pm 0.8$ \\
RV $(\%$ pred $)$ & $120 \pm 27^{*}$ & $91 \pm 29$ \\
TLC $(\%$ pred $)$ & $90 \pm 10$ & $88 \pm 8.0$ \\
RV/TLC $(\%)$ & $33.5 \pm 5.5^{*}$ & $24.7 \pm 6.9$ \\
MVV $(\%$ pred $)$ & $89 \pm 25.3$ & $120 \pm 47.6$ \\
\hline
\end{tabular}

Data are reported as means \pm SD. BMI: body mass index; AMC: arm muscle circumference; FFM: fat-free mass; FFMI: fat-free mass index; FVC: forced vital capacity; $F_{E V}$ : forced expiratory volume in $1 \mathrm{~s}$; RV: residual volume; TLC: total lung capacity; MVV: maximal voluntary ventilation; \% pred: percent of predicted. ${ }^{*} \mathrm{P}<0.05$, compared to control (unpaired $t$-test). 
Table 2. Peripheral muscle evaluation of patients with mitochondrial myopathy (MM) and healthy controls.

\begin{tabular}{lcc}
\hline & $\mathrm{MM}(\mathrm{n}=12)$ & Controls $(\mathrm{n}=10)$ \\
\hline Peripheral muscle strength & & \\
PT $\left(60^{\circ} / \mathrm{s} ; \mathrm{N} / \mathrm{m}\right)$ & $93.4 \pm 35.5^{*}$ & $150.2 \pm 43.9$ \\
PT $(\% \mathrm{pred})$ & $57.3 \pm 15.9^{*}$ & $78.6 \pm 16.8$ \\
IT $\left(60^{\circ} / \mathrm{s}\right)$ & $113.6 \pm 42.8^{*}$ & $157.6 \pm 51.9$ \\
TW $\left(300^{\circ} / \mathrm{s} ; \mathrm{J}\right)$ & $720.1 \pm 336.0^{+}$ & $1577.5 \pm 450.0$ \\
\hline
\end{tabular}

Data are reported as means \pm SD. PT: peak torque; $\mathrm{N} / \mathrm{m}$ : Newton/meter; IT: isometric torque; TW: total work; J: Joule; \% pred: percent predicted. ${ }^{*} \mathrm{P}<0.05$, ${ }^{+} \mathrm{P}<0.001$, compared to control (unpaired $t$-test).

supplementation, suggesting that L-carnitine did not influence body weight by decreasing fat mass (28).

No differences in peripheral muscle strength after Lcarnitine or placebo administration were observed, a finding that is in accordance with the results of a study in uremic patients with muscular atrophy. After 24-week treatment with L-carnitine $(2 \mathrm{~g}$ at the end of hemodialysis or twice daily in the dialysis solution), other studies

Table 3. Exercise responses of the patients with mitochondrial myopathy (MM) and the healthy controls during peak cycling exercise.

\begin{tabular}{|c|c|c|}
\hline & $\mathrm{MM}(\mathrm{n}=12)$ & Controls $(n=10)$ \\
\hline \multicolumn{3}{|l|}{ Metabolic } \\
\hline Work rate (Watts) & $88 \pm 28^{+}$ & $177 \pm 38$ \\
\hline$\dot{\mathrm{V}} \mathrm{O}_{2}(\mathrm{~mL} / \mathrm{min})$ & $1193 \pm 371^{+}$ & $2155 \pm 480$ \\
\hline$\dot{\mathrm{VO}}_{2}(\%$ pred $)$ & $64^{+}$ & 95 \\
\hline$\dot{\mathrm{V}}_{2 \mathrm{AT}}(\mathrm{mL} / \mathrm{min})$ & $704 \pm 273^{*}$ & $1013 \pm 261$ \\
\hline GER & $1.19 \pm 0.1$ & $1.20 \pm 0.08$ \\
\hline \multicolumn{3}{|l|}{ Ventilatory } \\
\hline$\dot{\mathrm{V}}_{\mathrm{E}}(\%$ pred $)$ & $47.4 \pm 14.3^{+}$ & $81.6 \pm 20.9$ \\
\hline f (ipm) & $28.8 \pm 8.5$ & $42.2 \pm 11.7$ \\
\hline $\mathrm{Vt}(\mathrm{mL})$ & $1372 \pm 357^{+}$ & $1991 \pm 404.2$ \\
\hline$\dot{\mathrm{V}}_{\mathrm{E} /} / \dot{\mathrm{V}} \mathrm{CO}_{2}$ & $30 \pm 4.85$ & $31 \pm 5.18$ \\
\hline$\dot{\mathrm{V}}_{\mathrm{E}} / \dot{\mathrm{V}}_{2}$ & $35.7 \pm 7.5$ & $38.1 \pm 6.0$ \\
\hline$\dot{\mathrm{V}}_{\mathrm{E} / \mathrm{MVV}}$ & $0.38 \pm 0.1^{*}$ & $0.57 \pm 0.15$ \\
\hline $\mathrm{PETCO}_{2}(\mathrm{mmHg})$ & $36.4 \pm 5.5$ & $37 \pm 5.73$ \\
\hline $\mathrm{PETO}_{2}(\mathrm{mmHg})$ & $101.1 \pm 6.7$ & $103.7 \pm 4.27$ \\
\hline \multicolumn{3}{|l|}{ Cardiovascular } \\
\hline HRmax (bpm) & $159 \pm 18^{*}$ & $177 \pm 8$ \\
\hline HR (\% pred) & $86 \pm 8^{*}$ & $95 \pm 4$ \\
\hline$\dot{\mathrm{V}} \mathrm{O}_{2} / \mathrm{HR}$ (mL/beat) & $7.5 \pm 2.8^{*}$ & $11.4 \pm 3.2$ \\
\hline$\dot{\mathrm{VO}}_{2} / \mathrm{HR}(\%$ pred $)$ & $77^{*}$ & 97 \\
\hline \multicolumn{3}{|l|}{ Symptoms } \\
\hline Borg dyspnea & 5 & 3 \\
\hline Borg dyspnea/VE & $0.111^{*}$ & 0.045 \\
\hline Borg LL & 7 & 8 \\
\hline Borg LL/WR & $0.096^{*}$ & 0.044 \\
\hline
\end{tabular}

Data are reported as means $\pm \mathrm{SD}$. $\dot{\mathrm{V}}_{2}$ : oxygen consumption; $\mathrm{AT}$ : anaerobic threshold; GER: gasexchange ratio; $\dot{V}_{\mathrm{E}}$ : minute ventilation; f: respiratory frequency; Vt: tidal volume; $\dot{\mathrm{V}} \mathrm{CO}_{2}: \mathrm{CO}_{2}$ output; $\mathrm{MVV}$ : maximal voluntary ventilation; $\mathrm{PETCO}$ : end-tidal $\mathrm{PCO}_{2} ; \mathrm{PETO}_{2}$ : end-tidal $\mathrm{PO}_{2}$; $\mathrm{HR}$ : heart rate; $\mathrm{LL}$ : lower limbs; WR: work rate; \% pred: percent predicted. ${ }^{*} \mathrm{P}<0.05,{ }^{+} \mathrm{P}<0.001$, compared to control (unpaired $t$ test). 
Table 4. Anthropometry, lung function and peripheral muscle performance of mitochondrial myopathy patients, after L-carnitine or placebo supplementation.

\begin{tabular}{lrr}
\hline & L-carnitine & \multicolumn{1}{c}{ Placebo } \\
\hline Anthropometry and lung volumes & & \\
BMI $\left(\mathrm{kg} / \mathrm{m}^{2}\right)$ & $20.4 \pm 1.1$ & $20.6 \pm 4.3$ \\
FFM $(\mathrm{kg})$ & $41.5 \pm 2.8$ & $42 \pm 9.3$ \\
FFMI $\left(\mathrm{kg} / \mathrm{m}^{2}\right)$ & $15.4 \pm 0.7$ & $15.6 \pm 2.4$ \\
AMC $(\mathrm{cm})$ & $20.3 \pm 0.9$ & $19.4 \pm 4.4$ \\
IC $(\mathrm{L})$ & $2.45 \pm 0.23^{*}$ & $2.26 \pm 0.22$ \\
IC $(\% \mathrm{pred})$ & $87 \pm 6.92^{*}$ & $83.5 \pm 6.40$ \\
Peripheral muscle tests & & \\
PT $\left(60^{\circ} / \mathrm{s} ; \mathrm{N} / \mathrm{m}\right)$ & $95.4 \pm 12.1$ & $93.4 \pm 35.5$ \\
IT $\left(60^{\circ} / \mathrm{s}\right)$ & $115.5 \pm 11.5$ & $113.6 \pm 42.8$ \\
TW $\left(300^{\circ} / \mathrm{s} ; \mathrm{J}\right)$ & $685.8 \pm 367.4$ & $720.1 \pm 336$ \\
\hline
\end{tabular}

Data are reported as means \pm SD. BMI: body mass index; FFM: fat-free mass; FFMI: fat-free mass index; AMC: arm muscle circumference; IC: inspiratory capacity; PT: peak torque; N/m: Newton/meter; IT: isometric torque; s: second; TW: total work; J: Joule; \% pred: \% predicted. ${ }^{*} \mathrm{P}<0.05$, compared to placebo (unpaired $t$-test).

reported an approximately $7 \%$ increase in the diameters of type I and type Ila fibers, but no marked changes in type IIb fibers (29-31). These findings suggest a specific effect of L-carnitine on oxidative metabolism without causing muscle hypertrophy $(31,32)$.

In our study, we observed a higher $\dot{\mathrm{V}}_{2}$ at Tlim and isotime during constant work exercise, and these findings were associated with significantly lower gas-exchange ratio values. This result supports our hypothesis that Lcarnitine supplementation increases muscle oxidative activity in patients with MM. Similarly, Gorostiaga et al.
(33) demonstrated that endurance athletes supplemented with a daily dose of $2 \mathrm{~g}$ of L-carnitine for 28 days had significantly lower values for gas-exchange ratio during a $66 \%$ of maximal CWR exercise, on a cycloergometer. They suggested that the lower gas-exchange ratio values after L-carnitine were related to increased lipid utilization by peripheral muscles during exercise (33). Our hypothesis for the increase in the CWR at Tlim and the increase of $\dot{\mathrm{V}} \mathrm{O}_{2}$ at both isotime and Tlim is that L-carnitine optimizes glucose utilization during high-intensity exercise. Under these conditions, carnitine could remove the

Table 5. Exercise responses of the patients with mitochondrial myopathy during the incremental cardiopulmonary exercise test, after L-carnitine or placebo supplementation at peak exercise.

\begin{tabular}{|c|c|c|}
\hline Peak & L-carnitine & Placebo \\
\hline \multicolumn{3}{|l|}{ Metabolic } \\
\hline Work rate (watts) & $90.5 \pm 9.4$ & $88.0 \pm 28.1$ \\
\hline$\dot{\mathrm{V}} \mathrm{O}_{2}(\mathrm{~mL} / \mathrm{min})$ & $1216.7 \pm 402$ & $1193 \pm 371$ \\
\hline Lactate (peak) (mM) & $6.4 \pm 3.0$ & $5.7 \pm 1.5$ \\
\hline Lactate (recovery) (mM) & $7.8 \pm 3.3$ & $8.7 \pm 3.5$ \\
\hline \multicolumn{3}{|l|}{ Ventilatory } \\
\hline$\dot{\mathrm{V}}_{\mathrm{E}}(\%$ pred $)$ & $50.4 \pm 15.0$ & $47.4 \pm 14.3$ \\
\hline \multicolumn{3}{|l|}{ Cardiovascular } \\
\hline $\mathrm{HR}(\mathrm{bpm})$ & $160 \pm 19$ & $159 \pm 18$ \\
\hline$\dot{\mathrm{V}} \mathrm{O}_{2} / \mathrm{HR}(\mathrm{mL} /$ beat $)$ & $7.5 \pm 2.6$ & $7.5 \pm 2.8$ \\
\hline \multicolumn{3}{|l|}{ Symptoms } \\
\hline Borg dyspnea & 4 & 5 \\
\hline Borg lower limbs & 7 & 7 \\
\hline
\end{tabular}

Data are reported as means $\pm \mathrm{SD}$. $\dot{\mathrm{V}}_{2}$ : oxygen consumption; $\dot{\mathrm{V}}_{\mathrm{E}}$ : minute ventilation; HR: heart rate; ICPET: incremental cardiopulmonary exercise test; peak: peak exercise in the ICPET; \% pred: \% predicted. There were no significant differences between groups $(\mathrm{P}>0.05$, unpaired $t$-test). 
Table 6. Metabolic, ventilatory and cardiovascular exercise variables at constant work rate (CWR) exercise at isotime and limit of tolerance (Tlim) in mitochondrial myopathy patients after L-carnitine or placebo supplementation.

\begin{tabular}{|c|c|c|}
\hline CWR & L-carnitine & Placebo \\
\hline \multicolumn{3}{|l|}{ Isotime } \\
\hline$\dot{\mathrm{v}}_{2}(\mathrm{~mL} / \mathrm{min})$ & $1151 \pm 115^{\star}$ & $1049 \pm 104$ \\
\hline GER & $1.03 \pm 0.04^{*}$ & $1.11 \pm 0.04$ \\
\hline$\dot{\mathrm{V}}_{\mathrm{E}}(\mathrm{L} / \mathrm{min})$ & $45 \pm 4$ & $45 \pm 4$ \\
\hline HR (bpm) & $157 \pm 5$ & $161 \pm 4$ \\
\hline$\dot{\mathrm{V}}_{2} / \mathrm{HR}$ (mL/beat) & $7.4 \pm 0.7$ & $6.8 \pm 0.6$ \\
\hline \multicolumn{3}{|l|}{ Limit of tolerance } \\
\hline Tlim (min) & $14 \pm 1.9^{*}$ & $11 \pm 1.4$ \\
\hline$\dot{\mathrm{VO}}_{2}$ at $\mathrm{Tlim}(\mathrm{mL} / \mathrm{min})$ & $1223 \pm 114^{*}$ & $1060 \pm 108$ \\
\hline GER & $1.4 \pm 0.01$ & $1.17 \pm 0.03$ \\
\hline$\dot{\mathrm{V}}_{\mathrm{E}}(\mathrm{L} / \mathrm{min})$ & $48.4 \pm 13$ & $47.8 \pm 14$ \\
\hline $\mathrm{HR}(\mathrm{bpm})$ & $159 \pm 18$ & $163 \pm 17$ \\
\hline$\dot{\mathrm{VO}}_{2} / \mathrm{HR}$ (mL/beat) & $7.7 \pm 2.4^{*}$ & $7 \pm 2.2$ \\
\hline
\end{tabular}

Data are reported as means $\pm \mathrm{SD}$. $\dot{\mathrm{V}} \mathrm{O}_{2}$ : oxygen consumption; isotime: 6 th min of exercise; Tlim: time limit of tolerance in the CWR exercise; GER: gas-exchange ratio; $\dot{V}_{E}$ : minute ventilation; HR: heart rate. ${ }^{*} \mathrm{P}<0.05$, compared to placebo (unpaired $t$-test)

excess acetyl groups that are formed during increased pyruvate oxidation, which predominantly occurs in type I muscle fibers. These effects maintain tricarboxylic acid cycle reactions and increase oxidative metabolism (3436), which translated into an increased Tlim in our patients. In addition, high-intensity exercise, both in normal and MM subjects, has been found to reduce muscle carnitine concentration by two mechanisms: i) the high rate of acylcarnitine formation $(7,36)$ and ii) increased metabolic oxidation of fatty acids (7). Indeed, up to an $85 \%$ reduction in muscle carnitine levels has been reported in patients with $\mathrm{MM}(7,37)$. Other studies have shown that in diseases with a primary or secondary carnitine deficiency, fatty acid oxidation occurs normally at rest but dramatically declines during prolonged exercise (cycloergometry) (34).

In conclusion, our findings suggest that at a higher rate of fatty acid utilization, L-carnitine supplementation was associated with a reduction in glucose metabolism, thus preserving glycogen content and ensuring maximum adenosine triphosphate oxidation rates. This was associated with fatigue reduction and improved exercise performance $(7,37)$.

\section{Study limitations}

The results of this study should only be applied to patients with MM and with CPEO who are without evidence of cardiovascular manifestations or a more severe form of the disease. In this regard, our patients were selected on the basis of a histopathological and clinical evaluation; their genotypic changes were not considered. We did not measure their plasma or muscle levels of carnitine, so we do not know whether these patients actually had a carnitine deficiency and/or how carnitine was retained in their muscles after supplementation. Another limitation was the small number of studied patients. However, they had all presented exclusively with CPEO at the Neuromuscular Diseases Clinic, Unifesp. However, in a post hoc analysis, this sample size resulted in significant power $(>80 \%)$ for the principal variable (Tlim) considered in this study (38).

Our results indicated that in patients with MM (CPEO form), a 2-month program of L-carnitine supplementation (3 g/day) led to an improvement in aerobic performance characterized by: i) longer Tlim during a high-intensity constant-work exercise and ii) increased $\mathrm{O}_{2}$ consumption measured at Tlim and isotime.

The influence of L-carnitine on oxidative metabolism in selected patients with MM provides insight into the regulation of skeletal muscle fat and carbohydrate oxidation during exercise. We suggest that these effects should be tested in future studies of patients with chronic and slowly-progressive muscle diseases such as MM.

\section{Acknowledgments}

This research was supported by FAPESP (07/559465). A.C. Gimenes was supported by CAPES as an MSC postgraduate fellow. L.E. Nery and J.A. Neder are established investigators (level II) of CNPq. 


\section{References}

1. DiMauro S, Lamperti C. Muscle glycogenoses. Muscle Nerve 2001; 24: 984-999, doi: 10.1002/mus.1103.

2. DiMauro S, Garone C. Metabolic disorders of fetal life: glycogenoses and mitochondrial defects of the mitochondrial respiratory chain. Semin Fetal Neonatal Med 2011; 16: 181189, doi: 10.1016/j.siny.2011.04.010.

3. Jeppesen TD, Schwartz M, Olsen DB, Wibrand F, Krag T, Duno $M$, et al. Aerobic training is safe and improves exercise capacity in patients with mitochondrial myopathy. Brain 2006; 129: 3402-3412, doi: 10.1093/brain/awl149.

4. Taivassalo T, Haller RG. Exercise and training in mitochondrial myopathies. Med Sci Sports Exerc 2005; 37: 20942101, doi: 10.1249/01.mss.0000177446.97671.2a.

5. Angelini C, Semplicini C. Metabolic myopathies: the challenge of new treatments. Curr Opin Pharmacol 2010; 10: 338-345, doi: 10.1016/j.coph.2010.02.006.

6. Scarpelli M, Cotelli MS, Mancuso M, Tomelleri G, Tonin P, Baronchelli $\mathrm{C}$, et al. Current options in the treatment of mitochondrial diseases. Recent Pat CNS Drug Discov 2010; 5: 203-209, doi: 10.2174/157488910793362412.

7. Brass EP. Supplemental carnitine and exercise. Am J Clin Nutr 2000; 72: 618S-623S.

8. Pfeffer G, Chinnery PF. Diagnosis and treatment of mitochondrial myopathies. Ann Med 2013; 45: 4-16, doi: 10.3109/07853890.2011.605389.

9. Murphy JL, Ratnaike TE, Shang E, Falkous G, Blakely EL, Alston CL, et al. Cytochrome c oxidase-intermediate fibres: importance in understanding the pathogenesis and treatment of mitochondrial myopathy. Neuromuscul Disord 2012; 22: 690-698, doi: 10.1016/j.nmd.2012.04.003.

10. Baecke JA, Burema J, Frijters JE. A short questionnaire for the measurement of habitual physical activity in epidemiological studies. Am J Clin Nutr 1982; 36: 936-942.

11. Marcovina SM, Sirtori C, Peracino A, Gheorghiade M, Borum P, Remuzzi G, et al. Translating the basic knowledge of mitochondrial functions to metabolic therapy: role of Lcarnitine. Transl Res 2013; 161: 73-84, doi: 10.1016/ j.trsl.2012.10.006.

12. Kraft M, Kraft K, Gartner S, Mayerle J, Simon P, Weber E, et al. L-Carnitine-supplementation in advanced pancreatic cancer (CARPAN) - a randomized multicentre trial. Nutr $J$ 2012; 11: 52, doi: 10.1186/1475-2891-11-52.

13. Pereira CA. Espirometria. In: Pereira CA, Neder JA (Editors), Diretrizes para testes de função pulmonar. Brasília: Sociedade Brasileira de Pneumologia e Tisiologia; 2014.

14. Neder JA, Andreoni S, Castelo-Filho A, Nery LE. Reference values for lung function tests. I. Static volumes. Braz J Med Biol Res 1999; 32: 703-717.

15. Neder JA, Andreoni S, Peres C, Nery LE. Reference values for lung function tests. III. Carbon monoxide diffusing capacity (transfer factor). Braz J Med Biol Res 1999; 32: 729-737, doi: 10.1590/S0100-879X1999000600008.

16. Whipp BJ, Davis JA, Torres F, Wasserman K. A test to determine parameters of aerobic function during exercise. $J$ Appl Physiol Respir Environ Exerc Physiol 1981; 50: 217221.

17. Beaver WL, Wasserman K, Whipp BJ. Bicarbonate buffering of lactic acid generated during exercise. J Appl Physiol
1986; 60: 472-478.

18. Neder JA, Nery LE, Peres C, Whipp BJ. Reference values for dynamic responses to incremental cycle ergometry in males and females aged 20 to 80. Am J Respir Crit Care Med 2001; 164: 1481-1486, doi: 10.1164/ajrccm.164.8. 2103007

19. Neder JA, Nery LE, Shinzato GT, Andrade MS, Peres C, Silva AC. Reference values for concentric knee isokinetic strength and power in nonathletic men and women from 20 to 80 years old. J Orthop Sports Phys Ther 1999; 29: 116126, doi: 10.2519/jospt.1999.29.2.116.

20. Robey RR. Reporting point and interval estimates of effectsize for planned contrasts: fixed within effect analyses of variance. J Fluency Disord 2004; 29: 307-341, doi: 10.1016/ j.jfludis.2004.10.005.

21. Roef MJ, Kalhan SC, Reijngoud DJ, De MK, Berger R Lactate disposal via gluconeogenesis is increased during exercise in patients with mitochondrial myopathy due to complex I deficiency. Pediatr Res 2002; 51: 592-597, doi: 10.1203/00006450-200205000-00008.

22. Masdeu MJ, Ferrer A. [Series 4: respiratory muscles in neuromuscular diseases and the chest cavity. The function of respiratory muscles in neuromuscular diseases]. Arch Bronconeumol 2003; 39: 176-183, doi: 10.1016/S03002896(03)75354-X.

23. Flaherty KR, Weisman IM, Zeballos RJ, Martinez FJ. The role of cardiopulmonary exercise testing for patients with suspected metabolic myopathies and other neuromuscular disorders. In: Weisman IM, Zeballos RJ (Editors), Clinical exercise testing. Basel: Karger; 2002. p 242-253.

24. Smits BW, Fermont J, Delnooz CC, Kalkman JS, Bleijenberg G, van Engelen BG. Disease impact in chronic progressive external ophthalmoplegia: more than meets the eye. Neuromuscul Disord 2011; 21: 272-278, doi: 10.1016/ j.nmd.2010.12.008.

25. Heinicke K, Taivassalo T, Wyrick P, Wood H, Babb TG, Haller RG. Exertional dyspnea in mitochondrial myopathy: clinical features and physiological mechanisms. Am J Physiol Regul Integr Comp Physiol 2011; 301: R873R884, doi: 10.1152/ajpregu.00001.2011.

26. Mancuso M, Angelini C, Bertini E, Carelli V, Comi GP, Minetti C, et al. Fatigue and exercise intolerance in mitochondrial diseases. Literature revision and experience of the Italian Network of mitochondrial diseases. Neuromuscul Disord 2012; 22 (Suppl 3): S226-S229, doi: 10.1016/j.nmd.2012.10.012.

27. Gimenes AC, Neder JA, Dal Corso S, Nogueira CR, Napolis $\mathrm{L}$, Mello MT, et al. Relationship between work rate and oxygen uptake in mitochondrial myopathy during rampincremental exercise. Braz J Med Biol Res 2011; 44: 354360, doi: 10.1590/S0100-879X2011000400013.

28. Chazot C, Blanc C, Hurot JM, Charra B, Jean G, Laurent G. Nutritional effects of carnitine supplementation in hemodiaIysis patients. Clin Nephrol 2003; 59: 24-30, doi: 10.5414/ CNP59024.

29. Brevetti G, Chiariello M, Ferulano G, Policicchio A, Nevola E, Rossini $A$, et al. Increases in walking distance in patients with peripheral vascular disease treated with L-carnitine: a doubleblind, cross-over study. Circulation 1988; 77: 767-773, 
doi: 10.1161/01.CIR.77.4.767.

30. Spagnoli LG, Palmieri G, Mauriello A, Vacha GM, D'Iddio S, Giorcelli G, et al. Morphometric evidence of the trophic effect of L-carnitine on human skeletal muscle. Nephron 1990; 55: 16-23, doi: 10.1159/000185912.

31. Giovenali P, Fenocchio D, Montanari G, Cancellotti C, D'Iddio S, Buoncristiani U, et al. Selective trophic effect of Lcarnitine in type I and Ila skeletal muscle fibers. Kidney Int 1994; 46: 1616-1619, doi: 10.1038/ki.1994.460.

32. Silverio R, Laviano A, Rossi FF, Seelaender M. I-carnitine and cancer cachexia: Clinical and experimental aspects. J Cachexia Sarcopenia Muscle 2011; 2: 37-44, doi: 10.1007/s13539-011-0017-7.

33. Gorostiaga EM, Maurer CA, Eclache JP. Decrease in respiratory quotient during exercise following L-carnitine supplementation. Int J Sports Med 1989; 10: 169-174, doi: 10.1055/s-2007-1024895.

34. Stephens FB, Constantin-Teodosiu D, Greenhaff PL. New insights concerning the role of carnitine in the regulation of fuel metabolism in skeletal muscle. J Physiol 2007; 581: 431-444, doi: 10.1113/jphysiol.2006.125799.

35. Constantin-Teodosiu D, Carlin JI, Cederblad G, Harris RC, Hultman E. Acetyl group accumulation and pyruvate dehydrogenase activity in human muscle during incremental exercise. Acta Physiol Scand 1991; 143: 367-372, doi: 10.1111/j.1748-1716.1991.tb09247.x.

36. Constantin-Teodosiu D, Cederblad G, Hultman E. PDC activity and acetyl group accumulation in skeletal muscle during prolonged exercise. J Appl Physiol 1992; 73: 24032407.

37. Campos Y, Huertas R, Lorenzo G, Bautista J, Gutierrez E, Aparicio $\mathrm{M}$, et al. Plasma carnitine insufficiency and effectiveness of L-carnitine therapy in patients with mitochondrial myopathy. Muscle Nerve 1993; 16: 150-153, doi: 10.1002/mus.880160205.

38. Cohen J. Statistical power analysis for the behavioral sciences. 2nd edn. Hillsdale: Lawrence Erlbaum Associates; 1988. 